\title{
Gebe Eğitimi
}

\section{Pregnancy Education}

Hüsniye DİNÇ ${ }^{1}$

Saadet YAZICI ${ }^{1}$

Tülay YILMAZ ${ }^{1}$

Sevil GÜNAYDIN ${ }^{1}$

${ }^{1}$ İstanbul Üniversitesi

Sağlık Bilimleri Fakültesi

Ebelik Bölümü

Yazışma Adresi

Correspondence

Hüsniye DINNÇ İstanbul

Üniversitesi Sağlı

Bilimleri Fakültesi Ebelik

Bölümü, Demirkapı Cad.

Karabal Sok. Bakırköy

Ruh ve Sinir Hastallklarl

Hastanesi Bahçesi içi,

34740, Bakırköy/İstanbul

husniyedinc@hotmail.com

Tel: 0 (212) 4141500

Geliş Tarihi/Received 04.06 .2014

Kabul Tarihi/Accepted 22.06.2014

HSP 2014;1(1):68-76
Özet: Gebelik süreci, eşlere anne baba olmayı öğrenme, uyum sağlama, planlama ve hazırlık yapma firsatı tanır. Anne baba adayları bu doğrultuda prenatal bakım ve yardım alma arayışı içinde olurlar. Gebe eğitimi; gebe kadın, eşi ve aile üyeleri için gebelik, doğum, doğum sonu döneme ve ebeveynliğe hazırlık amacıyla yürütülen eğitimleridir. Dünyanın her tarafinda yürütülen bu eğitimler birbirinden çok farklı özelliklere sahiptir. Bazı ülkelerde eğitim programları çok sistematik, programlı olarak yürütülürken bazılarında belirli bir program dâhilinde olmaksızın yürütülmektedir. Ülkemizde de gebe eğitim sınıfları ve kursları bazı özel kuruluşlarda, farklı isimlerle başlatılmış olup Sağlık Bakanlığı hastanelerinin hepsinde henüz yaygınlaşmamıştır. Bilindiği gibi ülkemizde sezaryen doğum oranlarının azaltılması, gebelik, doğum ve doğum sonu döneme ilişkin komplikasyonların önlenmesi doğum öncesi eğitim programlarının yaygınlaştırılmasıyla mümkündür. Doğum öncesi eğitim hizmeti ebelerin bağımsız işlevlerini yerine getirebileceği, önemli bir alandır. Bu derlemenin amacı; gebe eğitiminin ülkemizdeki ve dünyadaki güncel durumunu değerlendirmek ve gebe eğitiminin önemine dikkat çekmektir.

Anahtar Kelimeler: Gebelik; gebe eğitimi; ebelik.

Abstract: Pregnancy period gives the couple the opportunity to learn how to be a mother and father, to adapt, to plan and to prepare for the child. In this sense, the expectant mother and father are in search of prenatal care and receiving help. Pregnant education is carried out for the pregnant woman, her partner and family members, so as to get them ready for pregnancy, delivery, postpartum period and parenthood. These educations which are being done all over the world have very different characteristics than each other. In some countries the pregnant educations are carried out very systematically and programmed, while in some countries they are carried out without following a certain program. In Turkey pregnant education classes and courses have started in some private companies in various names; however, they are not very common in all the hospitals of Ministry of Health. As it is known, the reduction of deliveries by caesarean operation and the prevention of complications related to pregnancy and postpartum period are possible by the widespread application of education programs before delivery. Education services before delivery is a significant area where the midwives can fulfil their independent duties. The aims of the review: pregnant women to assess the current state of education in our country and around the world and draw attention to the importance of education is pregnant.

Keywords: Pregnancy; pregnant education; midwifery. 


\section{Giriş}

Gebelik ve doğum fizyolojik bir olay olarak kabul edilmekle birlikte kadın için stresli bir dönemdir. Özellikle ilk gebeliği olan anneler için doğum olayı korku ve heyecanla beklenir. Bu nedenle kadına verilecek destek ve eğitim önemlidir. ${ }^{1}$ On dokuzuncu yüzyılın sonlarına kadar bu destek aile ve sosyal çevre tarafından yapılmaktaydı. Günümüzde ise anne adaylarının doğum hakkındaki görüşleri ve beklentileri de değişmeye başlamış, artık kadınlar doğumlarını yönetmek ve doğumlarının merkezinde olmak, doğum ağrıları ile ilaçlar dışında kendi yöntemleri ile baş etmek ve bu deneyimi eşleriyle paylaşarak güzel bir doğum deneyimi yaşamak istemektedirler. ${ }^{2}$ Bu amaçla anne baba adayları sağlık kuruluşlarından danışmanlık almak, kitap okumak, yazılı basını takip etmek, doğuma hazırlık sınıflarına katılmak gibi çeşitli girişimlerde bulunmaktadır. ${ }^{3}$

Gebelik süreci, eşlere anne baba olmayı öğrenme, uyum sağlama, planlama ve hazırlık yapma fırsatı tanır. Gelişmiş ülkelerde çokça örnekleri bulunduğu gibi ülkemizde de bazı kuruluşlar tarafından genellikle çiftlerin birlikte katılımıyla gerçekleştirilen "ebeveyn sınıfı eğitim programları" ile aynı anlamda kullanılan; doğuma hazırlık sınıfları, doğum öncesi eğitim sınıfı, antenatal eğitim, ebeveyn eğitimi, perinatal eğitim, gebe eğitimi vb. birçok eğitim programı mevcuttur. Gebe eğitim sınıflarında temel amaç, ebeveynlerin gebelik, doğum ve doğum sonrası döneme uyumlarını sağlamak, normal doğumu desteklemek, farklı teknikler göstererek anne adayını ağrısız doğuma hazırlamak ve onları ebeveynlik konusunda yetkin hale getirmektir. ${ }^{4}$

$\mathrm{Bu}$ derlemenin amacı; gebe eğitiminin ülkemizdeki ve dünyadaki güncel durumunu değerlendirmek ve gebe eğitiminin önemine dikkat çekmektir.

\section{Gebe Eğitiminin Gebelik ve Doğum Üzerine Etkileri}

Prenatal bakımın hedefleri arasında sağlıklı bir bebeğin dünyaya gelmesini sağlamak, maternal riskleri azaltmak, komplikasyonlar açısından risk altındaki gebeleri belirlemek, problemleri önceden tahmin etmek ve önlemek, gebe eğitimi yapmak ve iletişim sağlamak sayılabilir. $^{5}$

Prenatal dönemde gebe eğitiminin birçok olumlu etkisi bulunmaktadır. Eğitimin eşler arasındaki ilişki ve annelik rolüne bağlanma üzerine olumlu etkisinin olduğ ${ }^{6}$ postpartum dönemde sosyal desteği arttırdığı, gebelerde sağlık bilincini yükselttiği, annenin gebelik ve doğum eylemi sorunlarıyla baş etme gücünü, doğum esnasında kendine güvenini sağladığı ve anksiyeteyi azalttığı ve normal doğuma eğilimi arttırdığ belirtilmektedir. $^{7,8}$ 
Normal doğum eylemi bilinen ve tanımlanan en şiddetli ağrı kaynaklarından biri olarak gösterilmektedir. Doğum ağrısının yönetimi anne bakımının temelini oluşturmaktadır. Bireyin ağrı algısı eğitim, kültür, halsizlik, uyku sorunları gibi faktörlerden etkilenmektedir. Ağrı ile baş etmede prenatal eğitimin etkili faktörlerden biri olduğu bilinmektedir. Bu eğitim doğum eylemi sırasında annenin rahatlamasını sağlamakta ve böylece doğum ağnısıyla baş etmesini kolaylaştırmaktadır. $^{9}$

\section{Gebe Eğitiminin Ülkemizdeki Durumu}

Ülkemizde Sağlıkta Dönüşüm Programı çerçevesinde "Sağlığın Teşviki ve Geliştirilmesi Programı" başlatılmış olup bu kapsamda üreme sağlı̆̆ı alanında hizmetlerin kullanılabilirliği ve erişilebilirliğinin arttırılması, hizmet kalitesinin yükseltilmesi amacıyla önemli gelişmeler elde edilmiştir. $\mathrm{Bu}$ gelişmelerin daha ileri seviyelere ulaşması açısından üreme sağlı̆̆ hizmetlerinde “Gebe Bilgilendirme Sınıfları”nın önemi vurgulanmıştır. Gebe Bilgilendirme Sınıfı programı ile tüm gebelerin, doğum öncesi, doğum ve doğum sonrası dönemlerine ilişkin bilgi sahibi olmalarını ve bilinçli doğum yapmalarını sağlamak amaçlanmış olup, sağlık personeline "Gebe Sınıfı" eğitici eğitimi düzenlenmiştir. $\mathrm{Bu}$ çalışmanın yaygınlaştırılması amacı ile eğitime katılan eğitimcilerin bu eğitimleri kendi bölgelerinde gerçekleştirmeleri ve sürekli hale getirmeleri planlanmıştır. Bu sayede hizmet standardının sağlanmasında önemli ilerlemeler elde edilmesi amaçlanmıştır. Yapılan çalışmaların temel hedefi anne bebek sağlığının geliştirilmesi ve anne ölüm oranlarının azaltılmasıdır. ${ }^{10}$

Ülkemizde 2005 yılında yapılan "Ulusal Anne Ölümleri Çalışması” sonuçlarına göre anne ölüm oranı yüz bin canlı doğumda 28,5 olup, bu ölümlerin \%62'si önlenebilir nedenlerden meydana gelmektedir. Sağlık Bakanlığı ulusal verisine göre 2010 yılı anne ölüm oranı ise yüz bin canlı doğumda 16,4'dür. Ülkemizde 1990-2008 yılları arasında anne ölümlerinde düşme eğilimi yakalanmıştır. Anne ölümlerinin önlenmesi ve kadınların insan hakları bağlamında temel sağlık hizmetlerinden yararlanmalarının temel ölçütlerinden birisi de doğum öncesi bakım hizmetlerinden yararlanmalarıdır. Türkiye Nüfus ve Sağlık Araştırmaları 2008 verilerine göre, Türkiye'de 2008 yılı öncesindeki beş yıllık dönemde doğum yapan annelerin \%92'sinin son doğumlarının gebeliği sırasında bir sağlık personelinden doğum öncesi bakım hizmeti aldığı görülmektedir. ${ }^{11,12}$

\section{Gebe Eğitiminin Dünyadaki Durumu}

Doğum öncesi eğitim programları sağlıklı bir gebeliğin geçirilmesi için dünya çapında önerilmektedir. ${ }^{14}$ Dünyada 1930 'lu y1llardan başlayarak doğum öncesi eğitim sınıfları 
açılmaya başlanmış, 1970'li yıllardan itibaren giderek artmıştır. Gebelerin doğum korkularının azaltılmasında doğum öncesi eğitim sınıflarının etkili olduğu bilinmektedir. ${ }^{4}$ 2001 Barcelona Anne ve Yeni doğan Hakları Bildirgesi'nde "Bütün kadınlar üreme sağlığı, gebelik, doğum ve yeni doğan bakımı ile ilgili bilgi ve yeterli eğitim alma hakkına sahiptir. Sağlık hizmetleri ve çalışanları böyle bir eğitimin kadına ve eşine sağlanmasından ve prenatal bakımın ayrılmaz bir parçası olan hazırlık dönemine eş ile birlikte katılmaları için özendirilmelerinden sorumludur." Ayrıca "Bütün kadınlar dünyada her ülkede hükümetler tarafından garanti altına alınmış, gereksiz risklerin uzaklaştırıldı̆̆ı ve doğru yardım alabildiği bir gebelik süreci geçirme hakkına sahiptir. Bütün kadınlar gebelik sırasında yeterli sağlık hizmeti ve koruyucu önlemleri hak eder. Gebelik sırasındaki sağlı hizmetlerinin nitelikli ve yeterli kaynaklara sahip olması gereklidir" maddeleri yer almıştır. ${ }^{13}$

Gelişmiş ülkelerde sigorta şirketleri gebe eğitimlerini desteklemektedir. Ayrıca sağlık sistemi de eğitime katılım konusunda bilinçlendirme yaptığı için, gebe eğitim sınıflarına katılım oranları yüksektir. İsveç’te ebeveyn eğitimi, ebeveyn destek programının bir parçası olarak devam etmektedir. Örneğin İsveç’te yapılan bir çalışmada antenatal eğitime katılım oranı \%78-93 olarak belirtilmektedir. ${ }^{16}$ İlk kez anne-baba olan ebeveynlerin antenatal eğitim algılarının değerlendirildiği başka bir çalışmada ise kadınların \%56'sı erkeklerin \%62'si antenatal eğitimin olumlu bir deneyim olduğunu belirtirken, kadınların \%68'i erkeklerin $\%$ 63'ü doğum sırasında faydalı olduğunu ifade etmişlerdir. ${ }^{17}$

Dünyanın her tarafında yürütülen antenatal eğitimler birbirinden çok farklı özelliklere sahiptir. Bazı ülkelerde eğitim programları çok sistematik, programlı olarak yürütülürken bazılarında belirli bir program dâhilinde olmaksızın yürütülmektedir. ${ }^{15}$ Ancak farklı ülkelerde yapılan çalışmalarda eğitimin etkili olduğu gösterilmiştir. İranlı kadınlarda perinatal eğitimin stres ve doğum ağrısına etkilerinin değerlendirildiği vaka kontrol çalışmasında, eğitim ve destekleyici görüşmelerin doğum ve bilinmeyen çevre korkusunu azalttığı belirtilmekle birlikte eğitimli kadınların doğum ağrısı ve problemlerle nasıl baş edeceğini öğrendiği belirtilmiştir. ${ }^{18}$ Ayrıca bu eğitim programları gebelikte fiziksel rahatsızlıkları ve anksiyeteyi büyük ölçüde engellemektedir. ${ }^{14}$

İspanya'da Artieta-Pinedo ve ark. ${ }^{19}$ tarafından antenatal eğitimin doğum sürecine faydalarının değerlendirildiği çalışmada 18-42 yaş arasında 616 nullipar gebe prospektif olarak değerlendirilmiştir. Çalışma sonuçlarına göre antenatal eğitim sınıfına katılan kadınların doğum esnasında daha az anksiyete yaşadığı saptanmıştır.

İngiltere'de Portland Hastanesi'nde gebeliğin 26-30 haftalar arasında başlayan, 6 hafta süren ve haftalık 2 saat eğitim verilen, benzer gebelik haftalarına sahip gebelerin oluşturduğu 
antenatal sınıflar bulunmaktadır. Bu 6 haftalık sürenin 5 haftası gebelik ve doğum dönemine, 1 haftası da doğum sonu döneme ait konularda bilgi ve beceri kazandırmayı hedeflemektedir. $\mathrm{Bu}$ konular geniş kapsamlı olup doğumun aşamaları, normal doğum, solunum egzersizleri, sezaryen ve emzirme gibi başlıca konuları içermektedir. ${ }^{20}$

Yine İngiltere'de King's College Hastanesi'nde bir ebe tarafından gebelik merkezi adlı bir proje başlatmıştır ve bu proje halen devam etmektedir. Bu proje çerçevesinde, gebelik haftaları birbirine yakın olan ve her grubun 8 ile 12 gebeden oluştuğu 6 grup oluşturulmuştur. Antenatal izlemlerde bu gruptaki gebelere bir arada iken ebe tarafından gebelik ve doğumla ilgili her konuda bilgi verilmektedir. Grup eğitiminin bir sonucu olarak da, gebelerin birbirleri ile iletişim kurmalarından dolayı gebeliğe ait daha az stres yaşadıkları belirtilmektedir. ${ }^{20}$

\section{Gebe Eğitim Sınıflarının İçerikleri}

Ülkemizde antenatal eğitim sınıfları için anne adaylarının gebeliğe uyumu ve öz bakımı, doğuma hazırlanması, tehlikeli durumları fark etmesi, doğum sonu kendi ve bebeğinin bakımı, emzirme ve postpartum kontrasepsiyon konularını kapsayan programlar hazırlanabildiği gibi bazı kuruluşlar tarafından eşlerin katılımıyla daha uzun süreli programlarda düzenlenebilmektedir. ${ }^{21}$

Gebe eğitim sınıflarında; gebelikte sağlık (anatomi, fizyoloji ve gebeliğin oluşumu), gebelikte oluşan fizyolojik değişiklikler, şikâyetler ve riskli durumlar, gebelikte günlük yaşam ve beslenme, annelik rolü ve iletişim, doğuma hazırlık, doğum ve doğumda ağrı kontrolü, doğum sonu dönem ve emzirme, yenidoğan bakımı ve gebelikte egzersiz konularında eğitim verilmektedir. $^{22}$

Gebelik sırasında kadınları sağlıklı tutmak ve gestasyonel diyabet ve gebelikte aşırı kilo alımını önleyebilmek amacıyla gebelikte fiziksel egzersiz uygulaması Amerikan Obstetrisyenler ve Jinekologlar Cemiyeti (ACOG) tarafindan tavsiye edilmekte ve doğum öncesi programa dâhil edilmesi önerilmektedir. ${ }^{14}$

\section{Gebe Eğitim Sınıflarında Uygulanabilen Eğitim Yöntemleri}

Doğum öncesi eğitim sınıflarında doğum ağrısının azaltılmasına veya yönetilmesine ilişkin Dick-Read, Bradley, Lamaze, Hipnoz gibi yöntemler bulunmaktadır. ${ }^{4,23}$ Bu yöntemlerin her biri doğumda kullanılmış ya da kullanılmaya devam etmektedir. Bu yöntemlerden bazılarının felsefesi kısaca şu şekildedir:

Dick-Read yöntemi: İngiliz obstetrisyen olan Grantly Dick-Read gebelik ve doğum olayını "anneliği tüm deneyimlerin ötesinde güzel ve ağrısız bir doğum” olarak tanımlamıştır. 
Read doğum ağrısının korku sonucu geliştiğini ve bu yöntemle "korku- gerilim- ağrı" zincirinin eğitim yolu ile parçalanabileceğini ve böylece ağrı ile baş edilebileceğini söyler. ${ }^{24}$

Bradly yöntemi: Doğumda solunum kontrolü ve abdominal solunumunun kullanılması genel vücut rahatlığını destekler. $\mathrm{Bu}$ yöntemde doğumda yalnızlık, karanlık ve sessizlik önemlidir. $^{24}$

Lamaze yöntemi: Bu yöntem anneyi bağırmak ya da kontrolü kaybetmek yerine, kontrollü kas gevşetme ve solunum modelleriyle uterus kasılmalarını taklit etmeye şartlandırır. Anne adayı her bir kontraksiyonun başlangıcında derin bir nefes alır, bunu kontraksiyon süresince alınan hızlı ve yüzeysel nefesler izler. Anne adayı düşüncelerini bir yer ya da objeye odaklamaya ve kas gevşemesine yoğunlaşmaya çalışır. Ayrıca yanındaki kişilerden sözlerle destek alır. ${ }^{24}$

\section{Gebe Eğitimi Verilirken Kullanılması Gereken İlkeler}

Eğitim verilecek grubun yetişkinlerden oluştuğu unutulmamalıdır. Ayrıca grubun özelliğinin bilinmesi, eğitim içeriğini, kullanılacak dili, eğitim yöntemini belirleme açısından önemlidir. Eğitim verilecek ortamın fiziksel koşullarının uygun olması eğitim etkinliği açısından değerlendirilmeli, grubun büyüklüğü tespit edilmeli ve uygun oturma düzeni oluşturulmalıdır. ${ }^{6}$

Gebe eğitimlerinin grup eğitimleri şeklinde yapılması anne adayları arasında ortak paylaşım sağladığından etkili bir yöntemdir. Gebe eğitim sınıflarında bilişsel ve davranışsal düzeyde gelişim sağlanabilmesi için eğitimlerin yetişkin öğrenme teknikleri kullanılarak, didaktik sunumlar, grup tartışmaları, videolar kullanılarak yapılması, görsel materyaller, resimli rehberler, şekilli poster ve modellerin kullanılmasına yer verilmesi önemlidir. ${ }^{15,25,26}$ Soru sorma, ilgileri dikkate alma, anahtar konumdaki noktaları vurgulayıp özetleme yapma grubun katılımını arttırır. ${ }^{27}$ Çünkü yetişkinler; aldıkları eğitimin kendi ihtiyaçlarına yönelik olmasını, eğitime etkin olarak katılmayı, konuyla ilgili tartışma, soru sorma ve uygulama fırsatlarının olmasını, eğitimin tekdüze olmamasını, kendilerine geribildirim verilmesini, eğitimin güvenli bir ortamda yapılmasını, kendilerinin bir birey olarak algılanmasını, özgüvenlerinin korunmasını ve eğitimcinin beceri, deneyim ve motivasyon açısından yeterli donanıma sahip olmasını beklemektedirler. ${ }^{25,27-29}$

\section{Sonuç}

Gebe eğitim ve desteğini sağlayacak sağlık personelinin başında ebeler ve hemşireler gelmektedir. Eğitimi veren sağlık personeli iyi bir grup lideri olmalı ve her grup üyesinin 
etkinliklere katılmasını desteklemeli, kadının karar sürecini etkileyebilecek faktörlerin sağlıklı bir şekilde değerlendirip, gebelik ve doğum sürecinin sağlıklı geçmesini sağlamalıdır. ${ }^{27} \mathrm{Bu}$ amaçla verilen doğuma hazırlık sınıfları son derece önemlidir. Özellikle kamuya bağlı sağlık kuruluşlarında bu konuda yapılan girişimlerin artırılması daha fazla anneye hizmet götürülmesini sağlayacaktır. Bu doğrultuda yapılacak gebe eğitimi sınıfları ile hem alınan doğum öncesi bakımın kalitesi arttırılmış olacak hem de doğum öncesi bakım hizmeti verme oranlarında artış gözlenecektir.

Ebelerin gebelik, doğum ve doğum sonu dönemde aktif rol alması ülkemizde normal doğum oranlarının artmasını ve sezaryen doğum oranlarının azalmasını sağlayacaktır. $\mathrm{Bu}$ nedenle ebelik bölümü öğrencilerinin mezuniyetten hemen önce "Gebe Eğitimi” programında yer alması bu istendik duruma katkı sağlayacaktır.

\section{Kaynaklar}

1. Sayıner FD, Özerdoğan N. [Natural birth] Doğal doğum. Maltepe Üniversitesi Hemşirelik Bilim ve Sanatı Dergisi 2009; 2(3):143-148.

2. Coşar F, Demirci N. [The effect of childbirth education classes based on the philosophy of lamaze on the perception and orientation to labour process] Lamaze felsefesine dayalı doğuma hazırlık eğitiminin doğum algısı ve doğuma uyum sürecine etkisi. Süleyman Demirel Üniversitesi Sağlık Enstitüsü Dergisi 2012; 3(1):18-30.

3. Yenal K, Okumuş H, Sevil Ü. [Determining pregnancy knowledge need by using webbased interactive antenatal counseling] Web ortamında interaktif- antenatal danışmanlık ile gebeliğe ilişkin bilgi gereksinimlerinin incelenmesi. Dokuz Eylül Üniversitesi Hemşirelik Yüksekokulu Elektronik Dergisi 2010; 3(1):9-14.

4. Coşkun A. [Pregnancy and reproductive health counseling] Gebelik ve üreme sağlı̆̆ danışmanlığı. 5. Uluslararası Üreme Sağlığı ve Aile Planlaması Kongresi Kitabı. (Ankara, 19-22 Nisan 2007) s.140-143.

5. American College of Obstetricians and Gynecologists (ACOG). Routine prenatal care and testing 2006. [Updated 2006; Cited 2 June 2014]. Available from: http://www.acog.org/ /media/Districts/District\%20VIII\%20Junior\%20Fellows/jfpc.pdf?d $\underline{\mathrm{mc}=1 \& \mathrm{ts}=20140221 \mathrm{~T} 0724379037}$

6. Mete S. [Antenatal education] Doğum öncesi eğitim. Şirin A. (editör). Kadın Sağlı̆̆1 Hemşireliği Kitabı. 1. Baskı. İstanbul: Bedray Basın Yayıncılık; 2008. p. 501-521.

7. Davis DK. Myles Midwifery a Textbook for Midwives. In: Henderson C, Macdonald S. 13 th ed. London: Elsevier Limited; 2004. 
8. Crawford J. Myles Text for Midwives. In: Fraser DM., Cooper MA. 15 th ed. London; Elsevier Limited; 2009. p.81-100.

9. Taşçı E, Sevil Ü. [Nonpharmacological approach intended for labor pain] Doğum ağrısına yönelik farmakolojik olmayan yaklaşımlar. Genel Tıp Dergisi 2007; 17(3): 181-186.

10. T.C. Sağlık Bakanlığı. Evlilik öncesi danışmanlık ve gebe sınıfı eğitimci eğitimi 2013. (Güncelleme Tarihi: 2013; Erişim Tarihi: 02 Haziran 2014) Erişim adresi: http://www.thsk.saglik.gov.tr/.../814-evlilik-\%C3\%B6ncesi dan\%C4\%B1\%C5\%9Fmanl\%C4\%B1k-ve-gebe-s\%C4\%B1n\%C4\%B1f\%C4\%B1-

11. Aile ve Sosyal Politikalar Bakanlığı Kadının Statüsü Genel Müdürlüğü. Türkiye’de kadının durumu 2012. (Güncelleme Tarihi: 2012; Erişim Tarihi: 02 Haziran 2014) Erişim adresi:

http://www.kadininstatusu.gov.tr/upload/kadininstatusu.gov.tr/mce/2012/trde_kadinin_durumu_20 12_ekim.pdf?p=1

12. Hacettepe Üniversitesi Nüfus Etütleri Enstitüsü. Türkiye Nüfus ve Sağlık Araştırmaları (TNSA) 2008. (Güncelleme Tarihi:2008; Erişim Tarihi: 02 Haziran 2014) Erişim adresi: http://www.hips.hacettepe.edu.tr/tnsa2008/

13. Declaration of Barcelona on the Rights of Mother and Newborn. 5th World congress of perinatal medicine to be held in Barcelona, 23-27 Sept. 2001, [Updated 23-27 Sept. 2001; Cited 21 Jan 2014]. Available from: http://www.escrh.eu/sites/escrh.eu/files/attachments/declarationofbarcelonaontherightsof motherandnewborn.pdf

14. Miquelutti MA, Cecatti JG, Makuch MY. Evaluation of a birth preparation program on lumbopelvic pain, urinary incontinence, anxiety and exercise: a randomized controlled trial. BMC Pregnancy Childbirth 2013; 13:154.

15. Mete S. [Antenatal education] Antenatal eğitim. 6. Uluslararası Üreme Sağlı̆̆ ve Aile Planlaması Kongresi Kitab1 (Ankara, 23-25 Nisan 2009) s.91-93.

16. Fabian HM, Radestad IJ, Waldenström U. Characteristics of Swedish women who do not attend childbirth and parenthood education classes during pregnancy. Midwifery 2004; 20(3):226-35.

17. Hildingsson I, Dalén K, Sarenfelt L, Ransjö-Arvidson AB. First-time parents' perception of antenatal education in Sweden. International Journal of Childbirth 2013; 3(1): 28-38.

18. Firouzbakht M, Nikpour M, Salmalian H, Ledari FM, Khafri S. The effect of perinatal education on Iranian mothers' stres and labor pain. Glob J Health Sci. 2013; 6 (1): 61-68. 
19. Artieta-Pinedo I, Paz-Pascual C, Grandes G, Remiro GF, Odriozola- Hermosilla I, Bacigalupe A, et al. The benefits of antenatal education for the childbirth process in Spain. Nursing Research 2010; 59(3): 194-202.

20. Toker E, Aktaş S. [Midwifery in England ] İngiltere'de ebelik. Maltepe Üniversitesi Hemşirelik Bilim ve Sanatı Dergisi 2010; 2(3): 89-97

21. İstanbul Üniversitesi İstanbul Tıp Fakültesi Kadın ve Çocuk Sağlığı Eğitim ve Araştırma Birimi. Doğum öncesi eğitim programı hazırlayanlar ve eğiticiler için rehber 2000 İstanbul: s.9-213.

22. T.C. Sağglık Bakanlığı Ana Çocuk Sağlığı ve Aile Planlaması Genel Müdürlüğü. Doğum öncesi bakım yönetimi rehberi 26 Şubat 2010. (Güncelleme Tarihi: 26 Şubat 2010; Erişim Tarihi: 02 Haziran 2014) Erişim adresi: http://www.saglik.gov.tr/TR/belge/110162/dogum-oncesi-bakim-yonetim-rehberi-genelgesi-2010--13.html

23. Serçekuş P. [Intervention for fear of childbirth: hypnobirthing] Doğum korkusu için müdahale: Hypnobirthing. TAF Prev. Med. Bull. 2011; 10(2): 239-242.

24. Kömürcü N, Berkiten EA. [Labor Pain and Management] Doğum Ağrısı ve Yönetimi. 1. Baskı. İstanbul: Bedray Basın Yayıncılık Ltd. Ști.; 2008; s.116-118.

25. Gagnon AJ, Sandall J. Individual or group antenatal education for childbirth or parenthood, or both. Cochrane Database Syst Rev. 2007; 18(3):1-61.

26. Okumuş H. [Prenatal maternal education: experience and results] Doğum öncesi anne eğitimi: deneyimler ve sonuçlar 1998-2006. 5. Uluslararası Üreme Sağlığı ve Aile Planlaması Kongresi Kitab1. (Ankara, 19-22 Nisan 2007) s.110-112.

27. Taşocak G. [Patient Education] Hasta Eğitimi. 2. Baskı. İstanbul: İstanbul Üniversitesi Basın ve Yayın Müdürlüğ̈̈; 2007. s.77-81.

28. Gökkoca ZU. [Health education in terms of adult education] Sağlık eğitimi açısından yetişkin eğitimi. Sürekli Tıp Ĕ̆itimi Dergisi 2001; 10(11); 412- 414.

29. Kakillioğlu T, Kurt Z, Dalkılınç M. Eğitim becerileri öğrenim rehberi. Ankara, Türkiye: T.C. Sağlık Bakanlığı Temel Sağlık Hizmetleri Genel Müdürlüğü İlkyardım ve Acil Sağlık Hizmetleri Daire Başkanlığı; 2002. (Güncelleme Tarihi:01 Temmuz 2002; Erişim $\begin{array}{llll}\text { Tarihi: } & 02 & \text { Haziran } & \text { 2014) }\end{array}$ http://xa.yimg.com/kq/groups/21508900/1990157512/name/E\%C3\%B0itim+Becerileri+K itab\%C3\%BD-son.doc 